\title{
Theologische Stellungnahmen zu den Grundlagen der politischen Kultur des Westens
}

\author{
LUdGer HoNNEFELDER
}

Menschenwürde und Menschenrechte.

Christlicher Glaube und die sittliche Substanz des Staates

Die politische Kultur des Westens und der christliche Glaube stehen zueinander in einem spannungsvollen Verhältnis: Der christliche Glaube ist von sich her nicht mit einer bestimmten politischen Kultur identisch, einer solchen gegenüber aber auch keineswegs neutral. Was wir die politische Kultur des Westens nennen, ist durch eine weitgehende Trennung von Kirche und Staat gekennzeichnet, in Herkunft und gegenwärtiger Wirklichkeit aber mit dem christlichen Glauben auf mannigfache Weise verbunden. Fragt man nach einer Instanz, die es erlaubt, die beiden so heterogenen Größen in ein Verhältnis zu setzen, so bietet sich in besonderer Weise das die politische Kultur des Westens kennzeichnende Verfassungsprinzip an. Denn in der Verfassung ist der "ethische Grundkonsens" der Gesellschaft formuliert und der konkreten politischen Wirklichkeit entgegengehalten. Als Ausdruck der dem Staat eigenen Ordnungsaufgabe und der diese Ordnung bestimmenden moralischen

${ }^{1} \mathrm{~J}$. Isensee, Demokratischer Rechtsstaat und staatsfreie Ethik, in: H. Marré/J. Stützing (Hg.), Essener Gespräche zum Thema Staat und Kirche, Bd.11, Münster 1977, $95 \mathrm{ff}$; vgl. insgesamt T. Rendtorff, Das Verfassungsprinzip der Neuzeit, in: A. Hertz/W. Korff / T. Rendtorff/ $\mathrm{H}$. Ringeling $(\mathrm{Hg}$.$) , Handbuch der christlichen Ethik, Bd. 2, Freiburg-$ Basel-Wien 1978, 215-233. 